\title{
RESPONSE \\ Some lessons learned from negative results of a randomized controlled trial for bladder reinnervation with the Xiao procedure
}

\author{
Gerald F. Tuite, MD, ${ }^{1,4,5}$ Ethan G. Polsky, MD, ${ }^{7}$ Yves Homsy, MD, ${ }^{7}$ Margaret A. Reilly, PT, ${ }^{2}$ \\ Carolyn M. Carey, MD, MBA, ${ }^{1,5}$ S. Parrish Winesett, MD, ${ }^{6}$ Luis F. Rodriguez, MD, ${ }^{1,5}$ \\ Bruce B. Storrs, MD, ${ }^{1,5}$ Sarah J. Gaskill, MD, ${ }^{5}$ Lisa L. Tetreault, RN, CCRP, ${ }^{3}$ \\ Denise G. Martinez, $\mathrm{MPH},{ }^{3}$ and Ernest K. Amankwah, $\mathrm{PhD}^{3}$
}

\begin{abstract}
${ }^{1}$ Division of Pediatric Neurosurgery, Neuroscience Institute, ${ }^{2}$ Department of Occupational and Physical Therapy, and ${ }^{3} \mathrm{Clinical}$ and Translational Research Organization, Johns Hopkins All Children's Hospital, St. Petersburg, Florida; ${ }^{2}$ Department of Pediatrics, Johns Hopkins Medicine, Baltimore, Maryland; ${ }^{5}$ Division of Pediatric Neurosurgery, Department of Neurosurgery and Brain Repair, and ${ }^{6}$ Division of Pediatric Neurology, Department of Pediatrics, University of South Florida, Tampa; and ${ }^{7}$ Children's Urology Group, Tampa, Florida
\end{abstract}

$\mathrm{W}$ E thank Drs. Kestle and Jea for their careful review of our work and for their insightful comments. ${ }^{2,3}$ Despite the "negative result" of this investigation, our study group and the majority of our patients are still very glad we embarked on this research endeavor. We all learned a great deal about the culture of clinical research, the value of careful planning before embarking on a clinical study, and the importance of perseverance in the face of widespread skepticism.

We were initially drawn to the Xiao procedure by our own patients. As word of Xiao's work reached the press and the internet, parents regularly asked us to begin performing the procedure on their children as soon as possible. Like our patients, we were initially very enthusiastic about the remarkable results described in Xiao's publications. However, after careful review of the published data, we grew concerned about the paucity of objective data and the small proportion of patients with follow-up. ${ }^{6.7}$ These concerns dampened our enthusiasm, allowing us to resist the temptation to be the neurosurgical pioneers and advocates of this procedure in the US without careful study.

Our academic evaluation of Xiao's work and our ultimate conclusion that a double-blind randomized controlled trial (RCT) was the best way to study this procedure seemed natural and honest. We were surprised by the degree of scrutiny and criticism we faced from organized academic medicine as we discussed our study design at national and international medical meetings as our study began. We were told repeatedly that an RCT was nearly impossible to perform in surgical patients, particularly in the pediatric neurosurgery setting. We were also dismayed that many leading academic physicians were so impressed with Xiao's early results that they openly criticized our RCT study design, citing the possible ethical problems of randomizing children to the placebo arm when we could so easily perform a simple intradural nerve anastomosis during spinal cord dethering. Our critics suggested that we were impeding the implementation of a procedure that held great promise. Fortunately, John Kusek, $\mathrm{PhD}$, and his colleagues at the National Institute of Diabetes and Digestive and Kidney Diseases consulted with our group early in the study. With John's thoughtful mentoring, we maintained our confidence in our study design and persevered in the face of criticism from many fronts.

With help from the National Institutes of Health, combined with steadfast support from our hospital (Johns Hopkins All Children's Hospital), from our affiliated universities (Johns Hopkins and the University of South Florida), and from neurosurgical organizations (AANS and CNS), we were able to take this research project to completion. Despite our detractors' pessimism about performing an RCT in children, our patients and their families fully 
supported the experimental design and they participated enthusiastically, even though they frequently asked study personnel to "break the code" and reveal to which group they were assigned.

Of course, we are deeply disappointed that none of our patients were able to achieve the dramatic voluntary bladder control that has been described by Xiao and colleagues. ${ }^{6,7}$ Our study certainly has limitations, but our results are in agreement with 2 recently published studies of the Xiao procedure in adults with neurogenic bladder dysfunction related to spinal cord injury. Rasmussen et al. ${ }^{4}$ in Denmark and Sievert et al..$^{5}$ in Austria both reported a similar lack of effectiveness of the Xiao procedure in their patients with spinal cord injury in very well-designed studies.

Even though we do not recommend that this procedure be performed in humans at this time, we are as motivated as ever to vigorously pursue avenues that will allow patients with neurogenic bladder dysfunction to regain control of their urination. We are indebted to Dr. C. G. Xiao for teaching us his technique and for sparking our interest in the field of bladder reinnervation research. We are hopeful that future animal and basic science research will provide more hope than the nerve transfer surgical techniques that have been pursued over the past century. ${ }^{1}$

Finally, we are hopeful that our experience performing a study that randomizes patients between different surgical arms will embolden other clinical investigators in pediatric surgical fields to more carefully consider an RCT when designing clinical research. Despite what is commonly suggested, we found that parents and their children were willing to randomize between surgical arms, once we ex- plained the rationale of our study and the risks involved. In the end, we owe our greatest debt to our brave and trusting patients and families, who allowed us to carefully study this procedure before its widespread implementation.

http://thejns.org/doi/abs/10.3171/2015.12.PEDS15710

\section{References}

1. Gomez-Amaya SM, Barbe MF, de Groat WC, Brown JM, Tuite GF, Corcos J, et al: Neural reconstruction methods of restoring bladder function. Nat Rev Urol 12:100-118, 2015

2. Jea A: Editorial. The positives of a negative study. $\mathbf{J}$ Neurosurg Pediatr [epub ahead of print May 3, 2016. DOI: 10.3171/2015.12.PEDS15633]

3. Kestle JRW: Editorial. The learning curve in surgical randomized controlled trials. J Neurosurg Pediatr [epub ahead of print May 3, 2016. DOI: 10.3171/2015.11.PEDS15623]

4. Rasmussen MM, Rawashdeh YF, Clemmensen D, Tankisi $\mathrm{H}$, Fuglsang-Frederiksen A, Krogh K, et al: The artificial somato-autonomic reflex arch does not improve lower urinary tract function in patients with spinal cord lesions. J Urol 193:598-604, 2015

5. Sievert KD, Amend B, Roser F, Badke A, Toomey P, Baron $\mathrm{C}$, et al: Challenges for restoration of lower urinary tract innervation in patients with spinal cord injury: a European single-center retrospective study with long-term follow-up. Eur Urol [epub ahead of print], 2015

6. Xiao CG: Xiao procedure for neurogenic bladder in spinal cord injury and spina bifida. Curr Bladder Dysfunct Rep 7:83-87, 2012

7. Xiao CG, Du MX, Li B, Liu Z, Chen M, Chen ZH, et al: An artificial somatic-autonomic reflex pathway procedure for bladder control in children with spina bifida. J Urol 173:2112-2116, 2005 